\title{
Esthetic Rehabilitation of Mutilated Maxillary Anterior Teeth under General Anesthesia in a Patient with Mild Intellectual Disability and Seizure Disorder
}

\author{
${ }^{1}$ Minimol K Johny, ${ }^{2}$ Rupesh S, ${ }^{3}$ Haeigin Tom Varghese, ${ }^{4}$ Benley George, ${ }^{5}$ Baby James
}

\begin{abstract}
Intellectual disability (ID) is one of the most common developmental disorders of childhood. Intellectual disability formerly known as mental retardation is a disability characterized by significant limitation in both intellectual function and adaptive behavior as expressed in conceptual social and practical adaptive skills. This disability originates before the age of 18 . Intellectual disability affects the mind, body and everyday life skills like thinking, talking and self care. People with disability often need extra help to attain and preserve good health which includes oral hygiene. Poor dental health which is prevailing in most of these children may further compromise their mental health; both of which may affect their psychological well being. There are numerous obstacles in delivering quality dental care under local anesthesia (LA) in ID children because of various behavioral problems. So general anesthesia is a safer and preferred option for such patients and currently it is a widely accepted treatment modality in rendering oral care in ID patients. This article describes a unique case of esthetic rehabilitation of maxillary anterior teeth in a 16 years old male patient under general anesthesia who was diagnosed with mild ID and seizure disorder.
\end{abstract}

Keywords: Caries, Esthetics, General anesthesia, Intellectual disability, Rehabilitation.

How to cite this article: Johny MK, Rupesh S, Varghese HT, George B, James B. Esthetic Rehabilitation of Mutilated Maxillary Anterior Teeth under General Anesthesia in a Patient

\footnotetext{
${ }^{1}$ Senior Lecturer, ${ }^{2,3}$ Reader, ${ }^{4}$ Reader and Head, ${ }^{5}$ Professor

1,5Department of Conservative Dentistry and Endodontics Pushpagiri College of Dental Sciences, Medicity, Perumthuruthy Thiruvalla, Kerala, India

${ }^{2}$ Department of Pedodontics, Pushpagiri College of Dental Sciences, Medicity, Perumthuruthy, Thiruvalla, Kerala, India

${ }^{3}$ Department of Prosthodontics Crown and Bridge, Pushpagiri College of Dental Sciences, Medicity, Perumthuruthy, Thiruvalla Kerala, India

${ }^{4}$ Department of Public Health Dentistry, Pushpagiri College of Dental Sciences, Medicity, Perumthuruthy, Thiruvalla, Kerala India

Corresponding Author: Minimol K Johny, Senior Lecturer Department of Conservative Dentistry and Endodontics Pushpagiri College of Dental Sciences, Medicity, Perumthuruthy Thiruvalla-689107, Kerala, India, Phone: 9048820602, e-mail: minimolkjohny@gmail.com
}

with Mild Intellectual Disability and Seizure Disorder. Cons Dent Endod J 2016;1(1):21-24.

Source of support: Nil

Conflict of interest: None

\section{INTRODUCTION}

Intellectual disability (ID) formerly known as mental retardation is a disability characterized by significant limitation in both intellectual function and adaptive behavior as expressed in conceptual social and practical adaptive skills. This disability originates before the age of $18 .^{1}$ Such lower intellectual functioning will lead to reduced ability to adapt to the needs of daily living which includes personal care. ${ }^{2}$

Intellectual disability is one of the most common developmental disorders of childhood. In India, incidence of the same is $3.1 \%$ in rural and $0.9 \%$ in urban area National Sample Survey Organisation (NSSO). According to International Classification of Diseases (ICD) 10 of World Health Organization (WHO) (2007), ID can be classified based on intelligence quotient levels as mild (50-69), moderate (35-49), severe (20-34), and profound $(<20)$. $^{3}$

Many people with ID also have other comorbid conditions, such as cerebral palsy, seizure or psychiatric disorders, attention deficit hyperactivity disorder, or problems with vision, communication and eating. Though language and communication problems are common in people with ID, motor skills are typically more affected when a person has coexisting conditions. ${ }^{4}$

Intellectual disability affects the mind, body and everyday life skills like thinking, talking and self care. People with disability often need extra help to attain and preserve good health. Oral health is no exception. ${ }^{5}$ Children with ID are the most vulnerable group as far as oral health is concerned because of the dependence on others for the management of self care. ${ }^{6}$ Children with severe ID and those from lower socioeconomic status are predominantly at risk with high dental needs and poor access to care. ${ }^{7}$ Regular usage of sweetened medications, slow oral clearance of food, preference for carbohydrate rich foods, impaired salivary flow are the common reasons for increased dental needs in people with ID. ${ }^{7,8}$ 
The most common oral health problems seen in patients with ID are poor oral hygiene, periodontal diseases, dental caries, malocclusion, etc. Prevalence of untreated dental caries, is however, high in patients with ID. ${ }^{5}$

One of the major drawbacks in rendering care, especially oral care to these patients is that the medical and dental teams work as two separate entities making cross referrals difficult. This often leads caregivers to seek dental care when symptoms dictate rather than for preventive care. Lack of awareness about the different modalities of available dental services among caregivers and low socioeconomic status are the other obstacles in delivering proper oral healthcare. ${ }^{9}$ Poor dental health which is prevailing in most of these children may further compromise their mental health; both of which may affect their psychological well being.

Though chairside dental treatment can be attempted in those with ID with behavioral modification techniques, there are numerous obstacles in delivering quality dental care under local anesthesia (LA) in ID children because of various behavioral problems like hyperactivity, impulsiveness, stubborn or fearful behavior, etc. So general anesthesia is a safer and preferred option for such patients and currently it is a widely accepted treatment modality in rendering oral care in ID patients. ${ }^{10}$

This article describes a unique case of esthetic rehabilitation of maxillary anterior teeth in a 16 years old male patient under general anesthesia who was previously diagnosed with mild ID and seizure disorder.

\section{CASE REPORT}

A 16-year-old male patient was referred from a private dental clinic to the Department of Dentistry, Pushpagiri Medical College Hospital, Thiruvalla. The patient presented with a chief complaint of painful decayed upper front teeth which was hampering his facial esthetics.

The medical history of the patient revealed mild ID and seizure disorder since childhood which was verified by a thorough evaluation of the patient at the Department

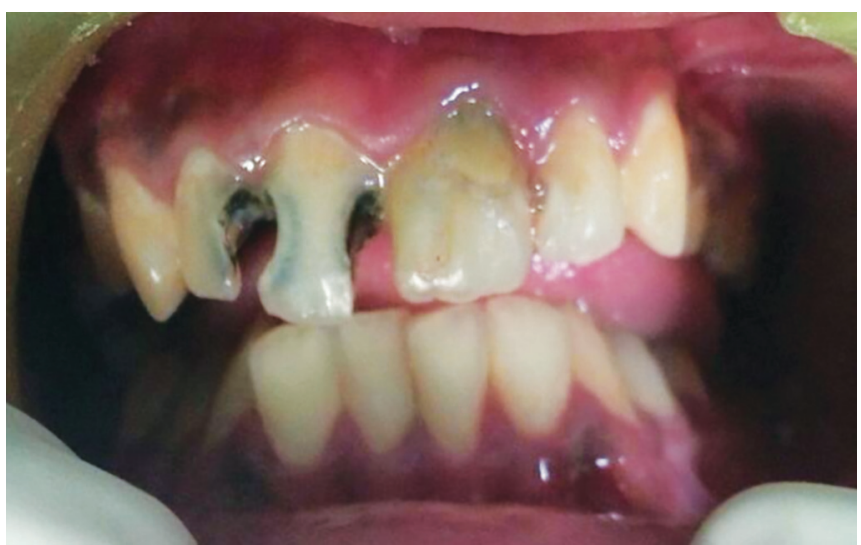

Fig. 1: Severely mutilated maxillary anterior teeth of Neurology, Pushpagiri Medical College Hospital. There was no relevant family history for the same. Dental treatment history (as told by the parent) revealed multiple previous failed chairside attempts at rendering dental care including oral prophylaxis, restoration and extraction under LA as the patient was uncooperative.

Intraoral examination of the patient's tongue, lip mucosa, buccal mucosa, hard and soft palate, and sublingual region revealed no pathological findings. Patient's oral hygiene was poor and presented with chronic generalized marginal gingivitis. Teeth numbers $12,11,21,22,44$ had deep multi surface caries which had an impact on his facial appearance and esthetics (Fig. 1). A root stump was seen in relation to 36 . Considering the patient's medical and emotional status, dental treatment was decided to be carried out under general anesthesia and informed consent was taken from the parents. Since the patient was not cooperative for intraoral radiographic examination, an orthopantomogram (OPG) (Fig. 2) was taken and a provisional treatment plan was formulated which comprised of root canal treatments of $13,12,11$, $21,22,23,44$ followed by placement of metal ceramic crowns for the same. Extraction of 36 root stump, oral prophylaxis, sealants in all remaining molars and premolars and fluoride application was also planned.

\section{Intraoperative Period}

Patient was admitted to the hospital one day prior and preanesthetic evaluation was completed. Nil per oral (NPO) was observed for 6 hours prior to the procedure. Nasotracheal intubation was carried out in order to obtain unobstructed access into the patient's mouth, which was kept open using a mouth prop. A saliva ejector was used to control oral moisture, and aspiration was prevented by placing moist sterile gauze in the pharyngopalatine area.

Initially full mouth prophylaxis was carried out and the oral cavity was rinsed with $2 \%$ chlorhexidine. ${ }^{11}$ After caries excavation, root canal treatment of six maxillary anterior teeth and tooth 44 were completed

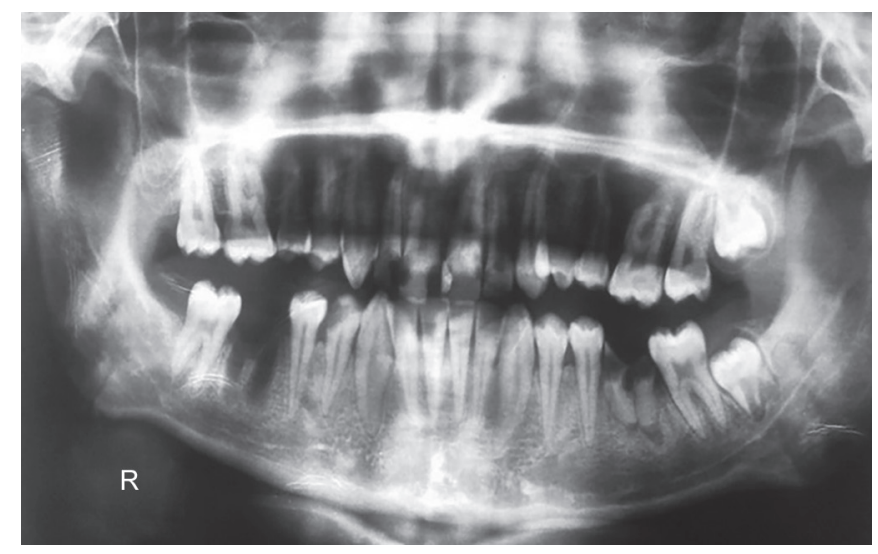

Fig. 2: Preoperative orthopantomogram 
using portable dental X-ray (DX3000, DEXCOWIN, Korea), VistaScan (indirect digital imaging system, Durr dental AG Germany), NSK iPex digital apex locator and ProTaper rotary system (Dentsply). Three percent sodium hypochlorite and normal saline were used as irrigants. Obturation was completed with ProTaper gutta percha points (Dentsply). AH plus (Dentsply) was used as the root canal sealer (Fig. 3). Access cavity was sealed with Filtek Z350 XT composite (3M ESPE). Following root canal therapy (RCT), crown preparation of the six anterior teeth was completed and temporary acrylic crowns were fabricated and cemented using zinc oxide eugenol cement. Sealant (Clinpro 3M ESPE) was applied to all susceptible pits and fissures of all molars and premolars. Extraction of root stump 36 was also carried out.

\section{Postoperative Period}

The oral cavity was cleaned thoroughly and retropharyngeal gauze was removed. Extubation was successfully accomplished following which the patient was transferred to the recovery room, where he recovered uneventfully. All dental procedures were completed without any problems, and the entire procedure took about 2 hours. After an oral examination, he was discharged from the hospital the next day with proper home care, oral hygiene and dietary instructions. Patient reported to Department of Dentistry after one week, during which metal try in for 21, 22, 23, 11, 12, 13 was done. Permanent metal ceramic crowns were cemented without necessitating any adjustments (Fig. 4). The patient and

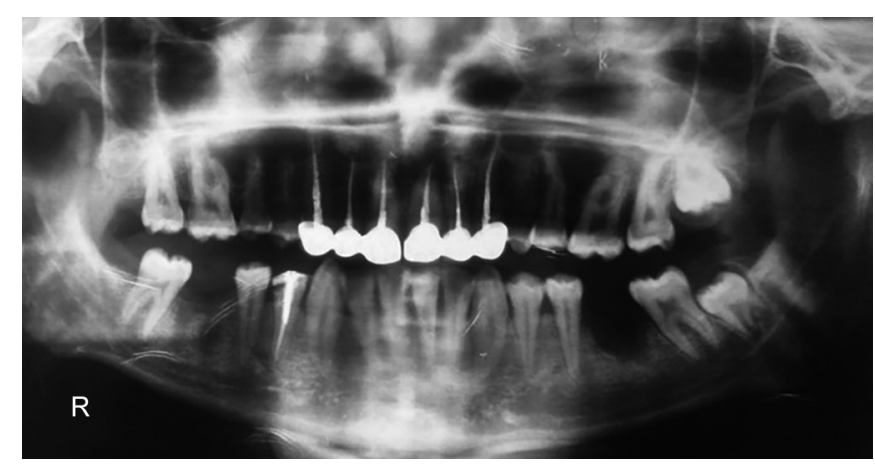

Fig. 3: Postoperative orthopantomogram

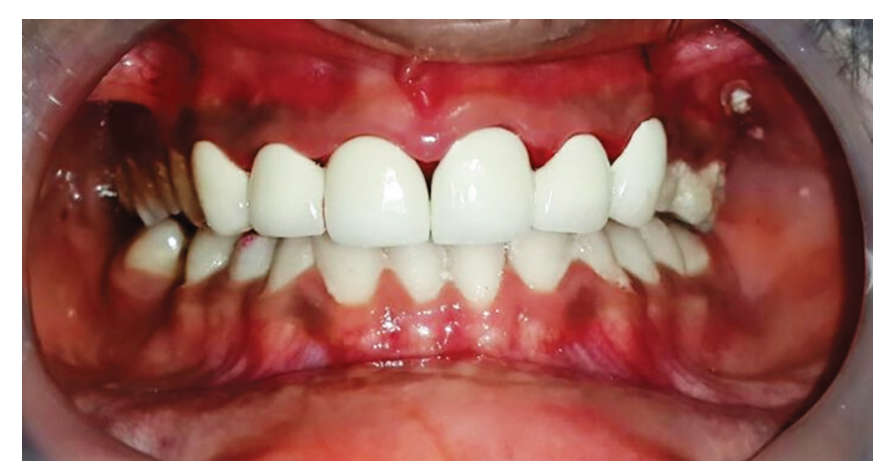

Fig. 4: Cementation of metal ceramic crowns the parents were instructed on maintaining a proper oral hygiene. The patient was then placed on a 3 months recall.

\section{DISCUSSION}

General anesthesia (GA) ensures efficient delivery of comprehensive dental treatment in a single appointment and necessitates little or no cooperation of the child. However, it is often the last resort because of the expense and risk-benefit considerations. ${ }^{12,13}$ In addition, some parents may find it hard to accept dental treatment for their children under GA. ${ }^{14}$ It is an alternative to chairside treatment under LA. It is a method of choice in some cases especially for medically compromised patients who cannot tolerate longer treatment times which may be unavoidable in complete oral rehabilitation situations. For patients with ID and seizure disorder, GA is an excellent alternative. The aim of treatment under GA is to restore the child's oral health in a single visit, allowing behaviormodification methods to be introduced more readily afterwards. ${ }^{15}$ The various advantages of GA include reduced intraoperative patient awareness and recall, possibility of prolonged treatment time, complete control of airway, breathing and circulation. Besides these, GA can also be administered rapidly and is easily reversible. The demerits like increased cost, need for hospital stay and GA complications, however, are far outweighed by the benefits of carrying out the treatment under GA.

In a study conducted in Mangalore, India in about 2823 children about 561 children with ID were identified, with $37.3 \%$ (209) in the rural with a prevalence rate of 3 per 1000 and $62.7 \%$ (392) in the urban area having a prevalence rate of 5 per $1000 .{ }^{16}$ Some Indian studies have reported a prevalence rate of psychiatric disorders in children ranging from 2.6 to $35.6 \% .{ }^{17}$ Prevalence rates ranging between $1 / 1000$ and $6 / 1000$ are reported from Ghana, Thailand, and Cuba. The prevalence of magnetic resonance (MR) was higher among males than in females $(\mathrm{p}<0.001)$ which are in support with other studies, ${ }^{18}$ but there was no notable sex difference between rural and urban areas.

Overall facial appearance plays a major role in the emotional development of patients with mild mental retardation. In the present case, on completion of esthetic oral rehabilitation, an enhanced self confidence, well being and an increased motivation for maintaining good oral hygiene was observed and reported by the parent.

Dental caries has evolved as a major public health problem in developing countries like India with the trend showing a constant increase. ${ }^{19}$ Studies have shown that dental caries not only affects child's appearance but it also affects learning Leaf et $\mathrm{al}^{20}$ behavior Gradella et $\mathrm{al}^{21}$ nutrition and general health Benzian et al. ${ }^{22}$ 
Awareness about the importance of dental health and various caries preventive measures should be made among the parents and caregivers of ID children. A multidisciplinary approach which includes medical and dental professionals should be carried out in order to enhance the quality of care given to ID children. ${ }^{23}$

\section{CONCLUSION}

This approach of using GA offers the advantage of providing extensive complete oral rehabilitation in a short period of time and in a single visit, allowing immediate relief of pain, even with little or no cooperation from the patient. However, it has little effect in promoting oral health and acceptance of routine dental care.

\section{ACKNOWLEDGMENT}

Dr Ivan (Assistant professor, Department of Anesthesia) and Dr A Devadattan (Professor and Head, Department of Conservative Dentistry and Endodontics), are acknowledged for their help rendered at various stages in the treatment planning and the oral rehabilitation procedure under general anesthesia.

\section{REFERENCES}

1. Schalock RL, et al. Intellectual disability: definition, classification, and systems of supports: American association of intellectual and developmental disabilities. 11th ed. Washington DC, 2010.

2. Horwitz SM, Kerker BD, Owens PL, Zigler E. Dental health among individuals with mental retardation. In the health status and needs of individuals with mental retardation. New Haven, CT: Yale University School of Medicine 2000;119-134.

3. The ICD-10 Classification of mental and behavioural disorders. Clinical descriptions and diagnostic guidelines. WHO (accessed on 07-01-2015) Available at: http://www.who. int/classifications/icd/en/bluebook.pdf?ua=1.

4. Practical oral care for people with intellectual disability. NIDCR (accessed on 07-01-2015). Available at: http://www.nidcr. nih.gov/oralhealth/Topics/DevelopmentalDisabilities/ PracticalOralCarePeopleIntellectualDisability.htm.

5. Shanbagh PP, Ram SM, Gupta B. Knowledge and oral health attitudes among care providers of children with intellectual disabilities: a cross sectional studies. J Contem Dent 2014 May-Aug;4(2):92-98.

6. Vigild M. Periodontal conditions in mentally retarded children. Com Dent Oral Epidemiol 1985;13(3):180-182.
7. Norwood KW Jr, Slayton RL. Oral health care for children with developmental disabilities. Pediatric 2013;131:614-619.

8. Thikkurissy SR, Lal S. Oral health burden in children with systemic diseases. Dent Clin North Am 2009;53(2):351-357.

9. Stiefel DJ. Dental care considerations for disabled. Adults Spec Care Dentist 2002;22(3):26S-39S.

10. Malhotra N. General anaesthesia for dentistry. Ind J Anaesth 2008;52:(Suppl 5):725-737.

11. Reddy $\mathrm{S}$, et al. Efficacy of $0.2 \%$ tempered chlorhexidine as a preprocedural mouth rinse: a clinical study. J Ind Soc Periodontol 2012 Apr-Jun;16(2):213-217.

12. Sun L. Early childhood general anaesthesia exposure and neurocognitive development. Brit J Anaesth 2010;105(1):i61-i68.

13. Atan S, Ashley P, Gilthorpe MS, Scheer B, Mason C, Roberts G. Morbidity following dental treatment of children under Intubation general anaesthesia in a day-stay unit. Int J Paediatr Dent 2004;14(1):9-16.

14. Savanheimo N, Vehkalahti MM, Pihakari A, Numminen M. Reasons for and parental satisfaction with children's dental care under general anaesthesia. Int J Paediatr Dent 2005;15(6):448-454.

15. Navit S, Katiyar A, Samadi F, Jaiswal JN. Rehabilitation of severely mutilated teeth under general anesthesia in an emotionally immature child. J Ind Soc Pedod Prev Dent 2010;28:42-44.

16. Bhagya B, Ramakrishna A. Prevalence of mental retardation among children in Mangalore NUJHS 2013 Dec;3(4). ISSN 2249-7110.

17. Sethi BB, Gupta SC, Kumar R, Kumar P. A psychiatric survey of 500 rural families. Ind J Psychiatry 1972;14:183-196.

18. Maulik PK, Harbour CK. Epidemiology of Intellectual Disability. In: JH Stone MB, editor 2013.

19. George B, et al. Dental caries: a strategic approach for prevention Afro-Asian. J Sci Tech 2014;1(2):160-166.

20. Leaf PJ, Bruce ML, Tischler GL, Holzer CE. The relationship between demographic factors and attitudes towards mental health services. J Community Pshychol 1987;15(2):275-284.

21. Gradella CM, Bernabe E, Bonecker M, Oliveira LB. Caries prevalence and severity and quality of life in Brazilian 2 to 4 years old children. Community Dent Oral Epidemiol 2011; 39(6):498-504.

22. Benzian H, Monse B, Heinrich-Weltzien R, Hobdell M, Mulder J, Helderman WP. Untreated severe dental decay: a neglected determinant of low body mass index in 12 years old Filipino children. BMC Public Health 2011;11:558.

23. Yashoda RR, Puranik MP. Oral health status and parental perception of child oral health related quality of life of children with autism in Bengaluru, India. J Indian Soc Pedod Prev Dent 2014;32(2):135-139. 